\title{
Trends and Determinants of Contraceptive Method Choice in China
}

\author{
MIN QIN $^{1}$, SABU S. PADMADAS ${ }^{2}$ AND JANE FALKINGHAM ${ }^{3}$
}

\begin{abstract}
${ }^{1}$ ESRC Center for Population Change, University of Southampton and China Population and Development Research Center, Beijing (email: min.qin@soton.ac.uk)

${ }^{2}$ Centre for Global Health, Population, Poverty \& Policy, China Research Centre and Department of Social Statistics and Demography, University of Southampton (email: S.Padmadas@soton.ac.uk)

${ }^{3}$ ESRC Centre for Population Change and China Research Centre, University of Southampton (email: J.C.Falkingham@soton.ac.uk)
\end{abstract}

\section{Address for correspondence}

Qin Min, $\mathrm{PhD}$

Center for Population Change

Faculty of Social, Human and Mathematical Sciences

University of Southampton

Highfield Campus

Southampton SO17 1BJ

United Kingdom

Tel: +44.23.8059.4382

Email: min.qin@soton.ac.uk

\section{Acknowledgement}

This research is supported by ESRC (ES/J500161/1). The authors thank the editors and anonymous reviewers, whose comments improved this article a great deal. 


\begin{abstract}
Contraception promotion is a crucial component of family planning programme in China. The state strategy has been gradually shifted from largely relying on mass mobilization and administrative means to client-centred informed choice since mid-1990s. Data are drawn from six national population and family planning surveys conducted during 1982-2006. Data from all six surveys are used for describing the trends in contraception use and method mix change over the last three decades. Individual level data from the 2001 and 2006 surveys are applied to investigate the effect of changing strategies on parity-specific methods uptake. Both individual and community level data from the 2006 survey are then used to examine the determinants of informed choice. Separate logistic multilevel models are fitted for each of the two outcomes. The contraceptive prevalence rate among married women of reproductive age in China was over 70 percent in the 1980s and reached 80 percent since 1990s. There was then a shift towards increased condom use and a decrease in sterilization among "new users" between 1996-2001 and 2001-2006. The multilevel analysis shows significant reductions in the uptake of methods encouraged by government programme between 1996-2001 and 20012006. The community contraception provision plays a positive role for informed choice. Although the historical top-down approach towards promoting long-acting methods has been weakening over time, the institutional pressure on individuals remains influential for the method choice. Enhancing community contraception provision and providing adequate counselling could significantly benefit informed contraceptive and in turn, could contribute to improving women's reproductive health.
\end{abstract}

Keywords: Contraceptive method Informed choice China 


\section{Background}

Contraception promotion is a crucial component of family planning programme in China. Since mid-1990s, the goal of national family planning programme has been shifted from an emphasis on demographic targets towards client-centred approaches and from a narrow focus on contraceptive prevalence towards relevant integration, with reproductive health and women's empowerment (NPFPC 2007; Xie 2011;Wang 2012a, 2012b). “Quality of Care” refocusing on clients' needs, informed choice and better quality services has been scaled up from a small scale pilot project in early 1990s into a national reform program after 2000 (Kaufman, Zhang and Xie 2006).

Globally, contraceptive use among married women of reproductive age has increased gradually in all developing countries since 1980. By the year 2000-2005, prevalence has reached 66\% in Asia, 73\% in Latin America and the Caribbean and 22\% in Sub-Saharan Africa. In terms of method mix, among all use, the share of the female sterilization rose from $29 \%$ to $39 \%$; the IUD declined from $24 \%$ to $20 \%$; the share of pill dropped from $16 \%$ to $12 \%$; the share of injectables rose from $2 \%$ to $8 \%$; the share of condom slight went up from $6 \%$ to $7 \%$; and the share of male sterilization remained below 3\% (Seiber, Bertrand and Sullivan 2007). The determinants of contraceptive use and method choice involve individual, cultural, fertility and contextual factors including family planning program efforts (Magadi and Curtis 2003; Philips et al 1988). Informed choice in family planning has been recognised as an important element of high quality reproductive health services (the Johns Hopkins School of Public Health 1989). The essential purpose of the informed choice process is to enable the client to make her/his own decision based on all necessary information from the client's perspective. Sizable evidence has been found that broadening the choice of contraceptive methods increases overall contraceptive prevalence (Philips et al. 1988; Jain 1989; Ross et al. 2001; Magadi and Curtis 2003). The provision of a wide range of contraceptive methods increases the opportunity for individual couples to obtain a method that suits their needs. Strong community-level influences on contraceptive service use has been found in different studies in countries such as India, Morocco and Bangladesh (Stephenson and Tsui 2002; Khan and Shaw 2011). Researchers also found that women's social, economic and demographic characteristics are associated with contraceptive method choice (Steele, Curtis and Choe 1999). In China, studies show that sterilization and IUD are the main methods married women used during the period of 1988-2001. Higher educated women are more 
likely to choose IUD; while lower educated are more likely to choose sterilization. Women in urban areas are more likely to choose IUD and condom, while those in rural areas are more likely to choose sterilization (Wang 2012b; Ren and Zheng 2006). A formal evaluation of the impact of the "Quality of Care" intervention in 30 pilot counties found that between 2003 and 2005, there were reductions in the prevalence of methods emphasized by official policy, but family planning workers continued to influence women's choices (Brown, Li and Padmadas 2010).

To date, there has been a notable lack of systematic national level analysis evaluating the impact of the change in the formal FPP strategy regarding method mix on women's contraceptive behaviour in China. Of the limited studies that have been conducted, some could not distinguish the timing of method being chosen and thus failed to capture the behaviour change precisely (Ren and Zheng 2006; Wang 2012b). Others failed to explore the unobserved contextual effects (Reng et al. 2003; Zhang 2007). This study, therefore, aims to contribute to the literature on contraceptive method choice in China by addressing this gap. The paper aims to 1) provide robust evidence of the change in method mix over time; 2) examine the effects of new client centred strategies on method mix, in particular focussing on changes in the uptake of methods advocated by policy; and 3) explore the determinants of contraceptive choice, including an assessment of the importance of contextual factors in that choice.

\section{Data and method}

This section describes the data source, analytical approach, and measurements considered in the study.

\section{Data}

Data for the analysis are draw from six national population and family planning surveys 1982-2006. The surveys (name of each survey is not necessarily the same) were conducted in 1982, 1988, 1992, 1997, 2001 and 2006 by the State Family Planning Commission of China. The main purpose of the series of surveys is to examine the fertility, contraceptive use and other reproductive health issues of women of reproductive ages (15-49). Retrospective full birth history information is available in all of the surveys, with the notable exception of the 1992 survey which recorded birth histories for only the last four children. All surveys were 
designed to be nationally representative, but for the exclusion of Tibet in 1982 and 2006 surveys. So for this study, Tibet is excluded from the analysis. The quality of this set of data has systematically assessed as being of high quality and consistent (Qin 2016). However, the questions in each survey are not exactly the same. For instance, a question concerning the start of the current episode of contraceptive method use appears only in 2001 and 2006 surveys. Data on both individual and community level information for the whole country is available only in the 2006 survey.

\section{Method}

\section{Descriptive analysis}

In order to address the first objective, all six surveys were used to provide a descriptive overview of trends in contraceptive use and the changes in method mix.

\section{Multilevel analysis I}

For the second objective, individual data from the 2001 and 2006 surveys were used to investigate the extent to which the uptake of parity-specific methods among women were influenced by the family planning programme. The analysis considered 32,409 currently married women out of a total of 39,508 women from the 2001 survey. Of these, 28,171 women were current users of contraception at the time of the survey. To capture the change of method choices, the sample was then further limited to only those new users who had commenced using a method between June 1996 and July 2001 (the 5-year period just before the survey). Women with no children (276 women) were excluded since they are not usually targeted by the family planning programmeand because they are less likely to be using longacting methods. This provided a final analysis sample of 9,492 new users in total - with 5,960 at parity one and the remainder at parity two or higher. A similar data selection procedure was then applied to the 2006 survey. For the analysis, 28,582 currently married women were selected from a total of 33,257 women. Of these, 24,176 were current users of contraception at the time of the survey. Only 7,611 women who had started using a method between August 2001 and September 2006 (the 5-year period just before the survey) were considered for the analysis. Again, women with no children (229 women) were excluded. This selection procedure yielded a data-set of 7,382 new users, with 4,683 at parity one and the rest at parity two or higher. 
Logistic multilevel models were fitted. The reasons for using a multilevel model are twofold. First, the data used for the analysis have a hierarchical structure, with women being selected from the household within each community, which in turn have been selected from the county and then from the province. Second, China's Family Planning Program is managed as a top-down process. Thus there are several levels of influence for the woman's choice of contraception. One study using Bangladesh Demographic and Health Survey data illustrated the tendency for the standard logistic model to seriously bias the parameter estimates of observed covariates when analysing multilevel data (Khan and Shaw 2011). To capture the influence of the hierarchical structure of family planning services delivery, a multilevel approach allowed integrating variables measured at different levels with unobserved exogenous effects.

The models take the form of four-level models with women (level 1) nested within communities (level 2), nested within counties (level 3) and nested within provinces (level 4). The first model is written:

$\operatorname{logit}\left(\mathrm{P}_{\mathrm{ijkm}}\right)=\beta_{0}+\beta_{\mathrm{t}} \mathrm{t}_{\mathrm{jkm}}+\beta_{1} X_{1 \mathrm{ijkm}}+\ldots \beta_{\mathrm{p}} X_{\mathrm{pjjkm}}+\delta_{1} \mathrm{Z}_{\mathrm{jkm}}+\delta_{2} \mathrm{Z}_{\mathrm{km}}+\delta_{3} Z_{\mathrm{m}}+\mathrm{u}_{0 \mathrm{jkm}}+\mathrm{v}_{0 \mathrm{~km}}+\mathrm{w}_{0 \mathrm{~m}}$

where subscript $\mathrm{i}, \mathrm{j}, \mathrm{k}, \mathrm{m}$ refers to level 1 , level 2, level 3 and level 4 respectively, $\mathrm{t}_{\mathrm{ijkm}}$ is a dummy variable that distinguishes two time periods, $\mathrm{x}$ variables refer to woman's characteristics, $\mathrm{z}$ variables capture the context effect at each level, with $\mathrm{u}, \mathrm{v}$, and $\mathrm{w}$ normally distributed random effects capturing the exogenous unobserved factors at each level. The outcome of principal interest was the random effect $\mathrm{W}_{0 \mathrm{~m}}$ and its associated variance $\sigma_{m}^{2}$ as a measure of the influence of the family planning programme on method choices. This effect was expected to be crucial taking into account the way in which family planning programmes operate in China. However, it was anticipated to weaken over time with the move towards an informed-choices approach. This changing influence was investigated by allowing $\sigma_{m}^{2}$ to be different for the two time periods - introducing a covariance term for the second time period.

First of all, separate models applying 2001 survey or 2006 survey data were fitted by parity, with the outcome being the method traditionally promoted by the family planning programme for her parity i.e. IUD use at parity one and sterilization at higher parities. Initial analysis showed some of the main effects to be similar; the models were combined with the inclusion of appropriate interactions. The fixed-effect model was then extended to incorporate the 
hierarchical structure of the data: women within communities within counties within provinces.

Outcome variable of Model (1): for the parity-one women, a response variable was created that contrasted IUD use with use of all other reversible methods and at parity two or higher, a response variable was created that contrasted the use of sterilization with the use of all other methods.

The explanatory variables are based on existing research, as described previously, which includes demographic characteristics (age, parity, year of marriage) and socio-economic characteristics (education, ethnicity, rural-urban residence, and region) of the woman. A dummy variable was included to distinguish between the two time periods covered by the surveys in order to measure the overall change across time. The province level in the multilevel analysis was of interest because the family planning policy was regulated at this level throughout China.

\section{Multilevel analysis II}

For the third objective, both individual and community level data from the 2006 survey were used to examine the factors including community variables influence the informed contraceptive method choice. Community data from the 2006 survey was merged with the individual dataset which included a sample of 7,611 currently married women who were current users of contraception and who had started using a method in the 5-year period just before the survey (including those women with no children). Among which, 243 cases with missing value of community variable were excluded. This selection procedure yielded a dataset of 7,368 new users.

Logistic multilevel models were fitted. The model is written:

$\operatorname{logit}\left(\mathrm{P}_{\mathrm{ijkm}}\right)=\beta_{0}+\beta_{1} X_{1 \mathrm{ijkm}}+\ldots \beta_{\mathrm{p}} X_{\mathrm{pijkm}}+\delta_{1} \mathrm{Z}_{\mathrm{jkm}}+\delta_{2} \mathrm{Z}_{\mathrm{km}}+\delta_{3} \mathrm{Z}_{\mathrm{m}}+\mathrm{u}_{0 \mathrm{jkm}}+\mathrm{v}_{0 \mathrm{~km}}+\mathrm{W}_{0 \mathrm{~m}}$

Since only one survey is used for this stage of the analysis, there is no time dummy variable. The rest of items are the same as the Model (1).

Outcome variable of Model (2) is whether the woman experienced an informed choice of contraception, contrasted with no informed choice. Informed choice of contraception is defined as those women who are currently using contraceptive where the decision regarding 
the choice of that method is being reported as being made by themselves or as part of a couple and who were aware of the side effect of the contraceptive. On the contrary, women had no informed choice either if the decision regarding the choice of contraceptive choice was reported as being made by a family planning worker or by others rather than the woman or couple, or if the woman did not understand the potential side effects of their current contraceptive use.

The explanatory variables for Model (2) includes not only demographic and socio-economic characteristics of the woman, but also a community level variable concerning contraception provision. This was measured based on a score variable constructed from six questions regards six types of contraception provision (condom, diaphragms, three types of oral pills and emergency pill) in the community. The response options were yes or no. A score of 1 was given to the "yes" response and of 0 to the "no" response to each question. Then the scores for the six questions are summed and recoded to 1 if the sum is lower than 3 reflecting a relatively limited method mix in contraception provision, and recoded 2 if higher than 3 reflecting relatively more varied contraception provision.

After fitting the models, the assumptions about random effects for both sets of multilevel logistic models were evaluated using normal probability plots for the individual, community, county and province level residuals. Statistic software MLwiN 2.32 is used for the multilevel modelling (Rasbash et al. 2009).

\section{Results}

\section{Trends in contraceptive prevalence and method choice 1982-2006}

Figure 1 shows the trends in contraceptive use by method among currently married women of reproductive age women in China from 1982 to 2006. Overall, contraceptive use among married women was high which increased from $71 \%$ in 1982 to over $80 \%$ after 1990s. The proportion of married women receiving sterilization increased from 35\% in 1982 to $54 \%$ in 1992 , and then steadily declined to $39 \%$ in 2006. In contrast to sterilization, the use of IUD steadily decreased from $50 \%$ in 1982 to $40 \%$ in 1992, and then increased to $48 \%$ in 2006. Interestingly, the proportion of women using the oral pill declined over time, from $8 \%$ in 1982 to just $1 \%$ in 2006; whilst condom use increased from $2 \%$ in 1982 to $10 \%$ in 2006. These method-specific trends show that the method mix in China has been dominated by sterilization and IUD. However sterilization has become less common in the most recent two 
decades, with the dominance of IUD use. Moreover, there has been a shift from oral pill to condom use.

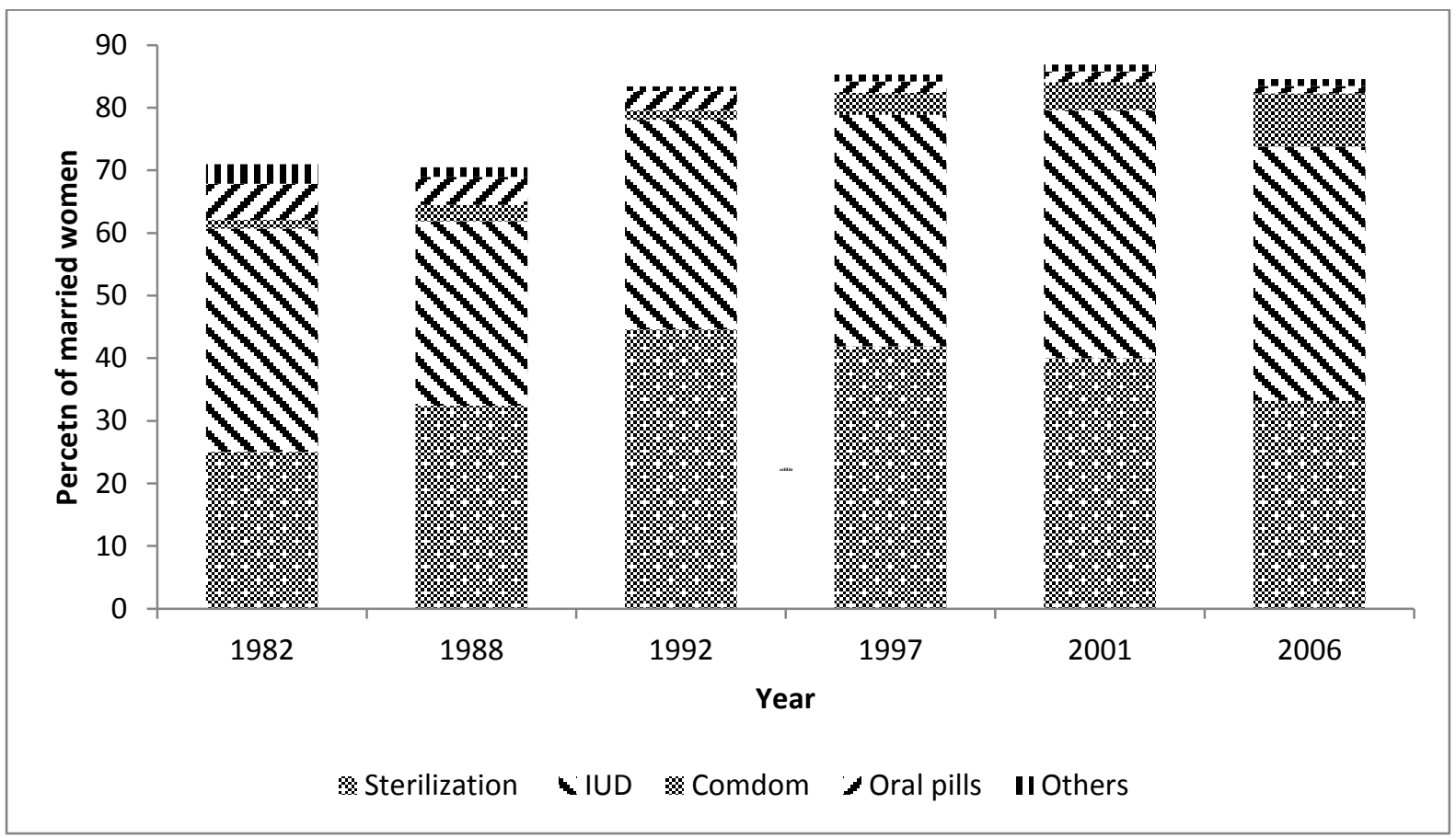

Figure 1. Trends in Contraceptive Method Choice (current use) among Married Women Aged 15-49, by Survey Year, China 1982-2006.

Table 1 provides evidence that over time, the family planning program in China extended the contraceptive options available to a substantial proportion among each group, reflecting that the implementation of FPP depends on the masses use of contraceptive measures. Group I are those urban residents nationwide; Group II are those rural residents in 6 provinces (Beijing, Tianjin, Shanghai, Jiangsu, Sichuan and Chongqing); Group III are those rural residents in 19 provinces (Hebei, Shanxi, Inner Mongolia, Liaoning, Jilin, Heilongjiang, Zhejiang, Anhui, Fujian, Jiangxi, Shandong, Henan, Hubei, Hunan, Guangdong, Guangxi, Guizhou, Shaanxi and Gansu); and Group IV are those rural residents in 5 provinces (Hainan, Yunnan, Qinghai, Ningxia and Xinjiang). This classification was motivated by the main types of differentiated Family Planning Policy implemented from 1984 onwards (Gu et al. 2007). 
Table 1. Contraceptive Prevalence Rate among Married Women Aged 15-49 by Groups, 1982-2006

\begin{tabular}{lrrrrrr}
\hline Groups & \multicolumn{1}{c}{$\mathbf{1 9 8 2}$} & \multicolumn{1}{c}{$\mathbf{1 9 8 8}$} & \multicolumn{1}{c}{$\mathbf{1 9 9 2}$} & \multicolumn{1}{c}{$\mathbf{1 9 9 7}$} & \multicolumn{1}{c}{$\mathbf{2 0 0 1}$} & \multicolumn{1}{c}{$\mathbf{2 0 0 6}$} \\
\hline I & 76.0 & 77.3 & 84.0 & 82.4 & 87.3 & 85.0 \\
II & 80.2 & 77.9 & 85.9 & 85.2 & 87.9 & 84.1 \\
III & 69.9 & 70.8 & 84.1 & 85.3 & 87.4 & 84.9 \\
IV & 38.7 & 50.4 & 67.9 & 68.8 & 75.9 & 80.1 \\
\hline
\end{tabular}

Calculated from 1982, 1988, 1992, 1997, 2001 and 2006 surveys

\section{Factors associated with the use of programme promoted methods}

Over the past two decades, there has been a clear shift in the use of contraceptive methods away from those traditionally encouraged by the family planning programme towards condom use at parity one and IUD use at parity two (Table 2). The percentage distribution of new users adopting methods formally promoted by the FPP (IUD use at parity one or sterilization at higher parities) by selected variables between 1996-2001 and 2001-2006 is shown in Table 3. The unadjusted figures show that there is a 13 per cent reduction in the choice of policy-driven methods between 1996-2001 and 2001-2006 (from 76.4\% to 63.5\%). Over the study period, the reduction in the choice of policy-driven methods is observed across individual groups with different age, education, urban and rural residence, ethnicity and regions (Table 3).The influence of family planning workers favoured by traditional programme still persists. There is however evidence that more couples are making their own choices of contraceptives. Amongst those using a programme driven method (IUD at parity 1 or sterilisation at parity 2), the percentage of women reporting that their choice was influenced by the family planning worker falls by 21 per cent between 1996-2001 and 20012006 (Figure 2). 
Table 2 Choice of Contraceptive Method among New Users by Parity (\%), China 1996-2001 and 2001-2006.

\begin{tabular}{|c|c|c|c|c|c|c|}
\hline \multirow[t]{2}{*}{ Method } & \multicolumn{3}{|c|}{$1996-2001(n=9492)$} & \multicolumn{3}{|c|}{$2001-2006(n=7382)$} \\
\hline & Overall & Parity one & $\begin{array}{l}\text { Parity two or } \\
\text { higher }\end{array}$ & Overall & Parity one & $\begin{array}{l}\text { Parity two or } \\
\text { higher }\end{array}$ \\
\hline IUD & 58.2 & 80.7 & 24.0 & 52.5 & 66.9 & 31.3 \\
\hline $\begin{array}{l}\text { Sterilization } \\
\text { (women) }\end{array}$ & 21.7 & 1.1 & 58.0 & 18.6 & 0.6 & 51.3 \\
\hline (men) & 4.1 & 0.1 & 11.2 & 2.2 & 0.1 & 6.1 \\
\hline Condom & 10.4 & 12.3 & 2.7 & 36.7 & 27.4 & 7.3 \\
\hline Oral pill & 3.4 & 3.8 & 2.1 & 3.0 & 2.8 & 1.9 \\
\hline Other & 2.1 & 2.0 & 2.1 & 2.1 & 2.2 & 2.1 \\
\hline Total women & 9492 & 5960 & 3532 & 7382 & 4683 & 2699 \\
\hline
\end{tabular}

Data source: 2001 and 2006 surveys

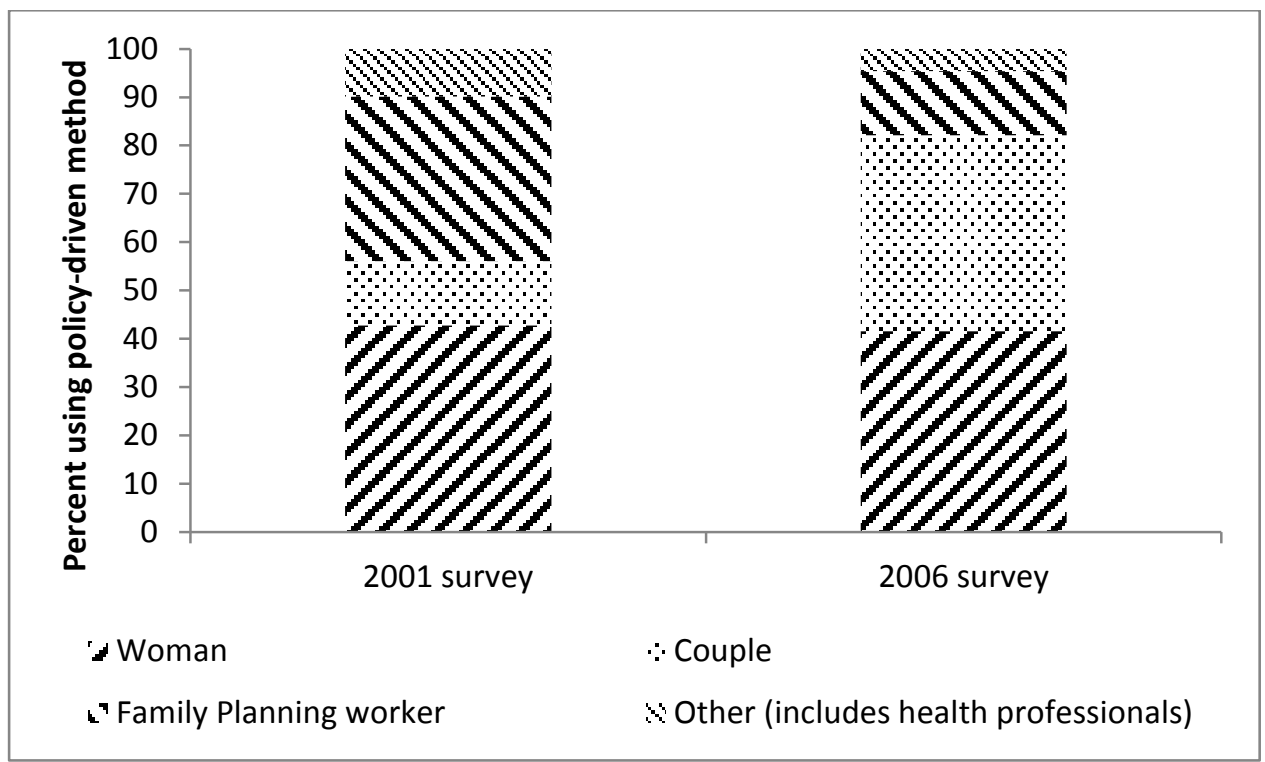

Figure 2 Source of Motivation for Current Contraceptive Method among New Users, China 19962001 and 2001-2006. Data source: 2001 and 2006 surveys 
Table 3 Percentage of New Users Adopting Policy-Promoted Methods ${ }^{\mathrm{a}}$ by Selected Variables, China 1996-2001 and 2001-2006.

\begin{tabular}{|c|c|c|c|c|}
\hline \multirow[t]{2}{*}{ Variables } & \multicolumn{2}{|c|}{ 1996-2001 } & \multicolumn{2}{|c|}{$2001-2006$} \\
\hline & Per cent & No. of women & Per cent & No. of women \\
\hline All & 76.4 & 9492 & 63.5 & 7382 \\
\hline \multicolumn{5}{|l|}{$\begin{array}{l}\text { Motivator for } \\
\text { current method }\end{array}$} \\
\hline Woman & 71.0 & 4061 & 61.4 & 3070 \\
\hline Couple & 62.8 & 1260 & 59.9 & 2989 \\
\hline $\begin{array}{l}\text { Family planning } \\
\text { worker }\end{array}$ & 89.5 & 3235 & 83.0 & 984 \\
\hline $\begin{array}{l}\text { Other (including } \\
\text { health } \\
\text { professionals) }\end{array}$ & 72.6 & 936 & 57.2 & 339 \\
\hline \multicolumn{5}{|l|}{$\begin{array}{l}\text { Current age (in } \\
\text { years) }\end{array}$} \\
\hline $15-24$ & 85.4 & 1110 & 70.5 & 1017 \\
\hline $25-34$ & 78.9 & 6765 & 66.7 & 4659 \\
\hline $35-49$ & 59.2 & 1617 & 50.5 & 1706 \\
\hline \multicolumn{5}{|l|}{ Year of marriage } \\
\hline Pre-1994 & 69.6 & 5189 & 50.4 & 1860 \\
\hline 1995-1999 & 84.7 & 4081 & 64.2 & 2025 \\
\hline Post-1999 & 78.8 & 222 & 70.0 & 3497 \\
\hline \multicolumn{5}{|l|}{ Parity } \\
\hline 1 & 80.7 & 5960 & 66.9 & 4683 \\
\hline $2+$ & 69.1 & 3532 & 57.4 & 2699 \\
\hline \multicolumn{5}{|l|}{$\begin{array}{l}\text { Woman's } \\
\text { education }\end{array}$} \\
\hline Primary or less & 78.4 & 4081 & 68.8 & 2145 \\
\hline $\begin{array}{l}\text { Lower middle } \\
\text { school }\end{array}$ & 78.9 & 3911 & 65.5 & 3566 \\
\hline $\begin{array}{l}\text { Upper middle } \\
\text { school and above }\end{array}$ & 64.0 & 1500 & 52.1 & 1671 \\
\hline \multicolumn{5}{|c|}{ Woman's ethnicity } \\
\hline Han & 78.1 & 8468 & 64.1 & 6475 \\
\hline Non-Han & 62.2 & 1024 & 58.7 & 907 \\
\hline \multicolumn{5}{|l|}{ Residence } \\
\hline Urban & 63.8 & 2331 & 44.7 & 2419 \\
\hline Rural & 80.4 & 7161 & 55.3 & 4963 \\
\hline \multicolumn{5}{|l|}{ Region } \\
\hline Eastern & 76.9 & 3649 & 59.2 & 3071 \\
\hline Central & 81.7 & 2902 & 72.2 & 2309 \\
\hline Western & 70.3 & 2941 & 59.9 & 2002 \\
\hline
\end{tabular}

Data source: 2001 and 2006 surveys

${ }^{a}$ Refers to IUD use at parity one or sterilization at higher parities

\footnotetext{
${ }^{1}$ This variable is based on the survey question and response options: "Who chose the current method? 1.Woman herself; 2.Spouse; 3.Couple; 4.Other family member/relative or friend; 5. Professional; 6. Family planning worker; 7. Other people”. The four categories are woman (option 1), couple (option 3), family planning worker (option 6) and Others (option 2,4,5,7).
} 
Regression analysis (Table 4) shows the effect of the explanatory variables from the multilevel logistic model predicting whether or not a woman's current choice of method is the one traditionally promoted by the family planning programme for her parity. The null model (without any covariate) is estimated first. The residual variance of the level-2, level-3 and level-4 were significant, indicating the need for multilevel modelling. The odds of a woman choosing a programme promoted method changes significantly over time as shown by the odds ratio of 0.60 for new users choosing such method in the five years prior to 2006 relative to those choosing method in the five years prior to 2001. The variance parameters for the variables analysed are also shown in Table 4. The random-effect variances are significant at the community, county and province levels. Usually, variances decrease at higher levels when these represent nested levels of geographic clustering. However, the results show that in this case the province-level variance is the largest, while the covariance term at the province level is not significant, suggesting that there is no evidence of any change in the random-effect distribution between the two time periods. The estimated variance at the province level is 0.61 , and about 67 per cent of the province random effects lie between -0.44 to +0.44 (one standard deviation). This generates odds ratios of between 0.65 and 1.55 , showing unexplained variation at the province level which is not unexpected given the topdown nature of the Chinese family planning programme.

The estimated odds ratios (based on interaction terms, see Table 4) of using a policy-driven method from different motivators by parity among Han and non-Han ethnic groups are shown in the Appendix Table 6. At parity one, the odds of using a policy-driven method are higher for women whose decisions are influenced by the family planning worker than for women making choices on their own. On the other hand, if women's decisions are made jointly with husbands or influenced by others, including health professionals, then the odds of using a policy-driven method are significantly lower when compared to women making decisions on their own. The association between the motivator for the method and use changes with parity. In general, the policy-promoted method is less popular at higher parities, as shown by the odds ratio of 0.12 for the women of parity two or higher using sterilization relative to women of parity one using IUD. Those married most recently are more likely to choose the policydriven method than their counterparts. The effect of woman's education is in the expected direction: women with lower levels of education are more likely to use policy-driven methods. 
Women living in rural areas and those in central region are also more likely to uptake the policy-driven method than those in urban areas. 
Table 4 Odds of Using a Policy-Driven Method ${ }^{\mathrm{b}}$ with Unadjusted Percentages in China 1996-2001 and 2001-2006 (results of four level logistic regression) $(n=16874)$

\begin{tabular}{|c|c|c|}
\hline Variables & Odds ratio [95 per cent $\mathrm{CI}]$ & Unadjusted percentage (n) \\
\hline \multicolumn{3}{|l|}{ Fixed effects } \\
\hline \multicolumn{3}{|l|}{ Survey } \\
\hline 2001 & 1.00 & $76.4(9492)$ \\
\hline 2006 & $0.60[0.38,0.94]^{*}$ & $63.5(7382)$ \\
\hline \multicolumn{3}{|l|}{ Motivator for current method } \\
\hline Woman & 1.00 & $66.8(7131)$ \\
\hline Couple & $0.40[0.35,0.46]^{* * *}$ & $60.7(4249)$ \\
\hline Family planning worker & $1.92[1.57,2.33]^{* * *}$ & $88.0(4219)$ \\
\hline Other (including health professionals) & $0.55[0.46,0.66]^{* * *}$ & $68.6(1275)$ \\
\hline \multicolumn{3}{|l|}{ Current age (in years) } \\
\hline $15-24$ & 1.00 & $78.3(2127)$ \\
\hline $25-34$ & $1.23[1.05,1.44]^{* *}$ & $74.0(11424)$ \\
\hline $35-49$ & $0.77[0.63,0.94]^{* *}$ & $54.8(3323)$ \\
\hline \multicolumn{3}{|l|}{ Year of marriage } \\
\hline Pre-1994 & 1.00 & $64.6(7049)$ \\
\hline 1995-1999 & $1.32[1.18,1.49]^{* * *}$ & $77.9(6106)$ \\
\hline Post-1999 & $1.30[1.09,1.55]^{* *}$ & $70.5(3719)$ \\
\hline \multicolumn{3}{|l|}{ Parity } \\
\hline 1 & 1.00 & $74.6(10643)$ \\
\hline $2+$ & $0.12[0.10,0.14]^{* * *}$ & $64.1(6231)$ \\
\hline \multicolumn{3}{|l|}{ Woman's education } \\
\hline Primary or less & 1.00 & $75.2(6226)$ \\
\hline Lower middle school & $0.89[0.77,1.02]$ & 72.5 (7477) \\
\hline Upper middle school and above & $0.60[0.48,0.74]^{* * *}$ & $57.7(3171)$ \\
\hline \multicolumn{3}{|l|}{ Woman's ethnicity } \\
\hline Han & 1.00 & $72.0(14943)$ \\
\hline \multirow{2}{*}{\multicolumn{3}{|c|}{ Residence }} \\
\hline & & \\
\hline Urban & 1.00 & $59.5(4750)$ \\
\hline Rural & $2.10[1.86,2.36]^{* * *}$ & $75.1(12124)$ \\
\hline \multicolumn{3}{|l|}{ Region } \\
\hline Eastern & 1.00 & $68.8(6720)$ \\
\hline Central & $1.77[1.00,3.12]^{*}$ & $77.5(5211)$ \\
\hline Western & $1.35[0.80,2.29]$ & $66.3(4943)$ \\
\hline \multicolumn{3}{|l|}{ Interactions } \\
\hline Parity2+*Non-Han & $0.32[0.24,0.42]^{* * * *}$ & $44.5(1010)$ \\
\hline Parity $2+*$ Couple & $6.82[5.50,8.46]^{* * *}$ & $64.6(1613)$ \\
\hline Parity2+*FP worker & $3.42[2.60,4.50]^{* * *}$ & $84.3(2095)$ \\
\hline Parity2+*Other & $4.06[2.85,5.77]^{* * *}$ & $63.8(414)$ \\
\hline Random effects & Null model without covariates & Model with covariates \\
\hline Province level variance and standard error & $0.93(0.21)^{* * *}$ & $0.61(0.19) * * *$ \\
\hline Covariance and standard error & & $-0.03(0.14)$ \\
\hline County level variance and standard error & $0.64(0.08)^{* * *}$ & $0.57(0.07) * * *$ \\
\hline Community variance and standard error & $0.42(0.04) * * *$ & $0.40(0.05) * * *$ \\
\hline
\end{tabular}




\section{Determinants of informed method choice}

The parameter estimates from the multilevel multivariate model of the determinants of informed method choice are presented in Table 5. The null model is estimated first. The residual variance of the level-2 and level-3 were significant. The analysis shows that after controlling for women's individual characteristics, the degree of variation in contraception provision available in the community plays important role. The odds of making an informed choice of contraception amongst women living in a community where more than three types of contraception are available is 1.5 times of those living in a community with availability of only a limited method mix. Method itself also influences the likelihood of informed choice. Compared with IUD, new users currently using a condom have significantly higher odds of informed choice, while those with sterilization have a lower odds of informed choice. The effects of other individual characteristics are as expected. Women with higher education have higher odds of informed choice than those with lower education. Rural residents have lower odds than their urban counterparts. Women living in China's central region have the lowest odds of informed choice of contraception compared with those living in the eastern and western regions. In contrast to the results in model (1) (Table 4), it is found that community level variance is greater than the county level and province level (Table 5), highlighting the importance of local implementation for informed choice.

The assumptions about random effects were validated for the both multilevel logistic model (1) and model (2), using normal probability plots for the individual, community, county and province level residuals (Rasbash et al. 2009). The results confirmed the normality assumption. 
Table 5 Odds of Informed Choice of Contraception ${ }^{c}$ (results of four level logistic regression) ( $\mathrm{n}=7368$ )

\begin{tabular}{|c|c|c|}
\hline Variables & OR (95 per cent CI) & Unadjusted percentage (n) \\
\hline \multicolumn{3}{|l|}{ Fixed effects } \\
\hline \multicolumn{3}{|l|}{ Current age } \\
\hline $15-24(\mathrm{ref})$ & 1.00 & $61.6(1052)$ \\
\hline $25-34$ & $1.22[1.02,1.44]^{*}$ & $62.4(4644)$ \\
\hline $35-49$ & $1.15[0.93,1.41]$ & $58.9(1672)$ \\
\hline \multicolumn{3}{|l|}{ Ethnicity } \\
\hline Han (ref) & 1.00 & $60.6(6454)$ \\
\hline Non-Han & $1.20[0.91,1.58]$ & $68.1(914)$ \\
\hline \multicolumn{3}{|l|}{ Education } \\
\hline Primary or less (ref) & 1.00 & $48.0(2141)$ \\
\hline Lower middle school & $1.64[1.42,1.89] * * *$ & $62.1(3565)$ \\
\hline Upper middle school and above & $3.00[2.42,3.71] * * *$ & $77.4(1667)$ \\
\hline \multicolumn{3}{|l|}{ Residence } \\
\hline Urban (ref) & 1.00 & $70.4(2352)$ \\
\hline Rural & $0.97[0.78,1.21]^{*}$ & $57.3(5016)$ \\
\hline \multicolumn{3}{|l|}{ Region } \\
\hline Eastern (ref) & 1.00 & $67.0(3085)$ \\
\hline Central & $0.55[0.38,0.78] * * *$ & $53.6(2273)$ \\
\hline Western & $0.71[0.49,1.04]$ & $61.9(2010)$ \\
\hline \multicolumn{3}{|l|}{ Contraception } \\
\hline IUD（ref） & 1.00 & $62.2(3878)$ \\
\hline Male/female sterilization & $0.64[0.54,0.76] * * *$ & $44.3(1570)$ \\
\hline Condom & $1.57[1.33,1.85] * * *$ & 74.5 (1574) \\
\hline Others & $1.45[1.08,1.94]^{*}$ & $71.7(346)$ \\
\hline \multicolumn{3}{|l|}{ Types of methods community provided } \\
\hline Less than 3 (ref) & 1.00 & $53.4(1866)$ \\
\hline More than 3 & $1.48[1.19,1.85]^{* * *}$ & $64.2(5502)$ \\
\hline Random effects & $\begin{array}{l}\text { Null model without } \\
\text { covariates }\end{array}$ & Model with covariates \\
\hline Province level variance and standard error & $0.16(0.1)$ & $0.02(0.04)$ \\
\hline County level variance and standard error & $0.62(0.13) * * *$ & $0.36(0.09) * * *$ \\
\hline Community variance and standard error & $1.05(0.09) * * *$ & $1.01(0.09)^{* * *}$ \\
\hline
\end{tabular}

Data source: 2006 survey

${ }^{\mathrm{c}}$ Refers to woman had the informed choice of contraception, contrasted with no informed choice

CI: Confidence Interval; ${ }^{*} \mathrm{p}<.05 ; * * \mathrm{p}<.01 ; * * * \mathrm{p}<.001$ 


\section{Discussion}

The results show that contraceptive prevalence among married women of reproductive age increased from a high level of $70 \%$ in the 1980s to an even higher level of $80 \%$ after the 1990s (Figure 1). The prevalence rate in China is much higher than that of other developing regions-66\% in Asia, 73\% in Latin America and the Caribbean, and only 22\% in SubSaharan Africa in 2000-2005 (Seiber, Bertrand and Sullivan 2007). The high contraception prevalence in China is reversely associated with the rapid fertility decline, which owes much to the social and economic development and the government's family planning policy (Li 2009). Our results also demonstrate that sterilization and IUD remain the most popular method in China over time, though sterilization is slightly less prevalent after the 1990s. The overall proportions of users relying on female sterilization and IUD are around $42 \%$ and $20 \%$ in Asia in 2000-2005 (Seiber, Bertrand and Sullivan 2007); the corresponding figures in China are $39 \%$ and $48 \%$ respectively. The potential underlying mechanisms of consistency high level of sterilization and IUD use might be that given the strict birth control regulations in China, the majority women could have only one or two children during their entire reproductive lifespan. Most women have finished childbearing by their early thirties, and need methods to prevent unwanted pregnancy. In such circumstances, the long-acting and effective method such as female sterilization and IUD might be sensible choices. The data also show a steady increase of condom use in China. This change in contraceptive behaviour could reflect the policy restrictions on parity-specific method requirements were being relaxed. It also could reflect demographic changes such as higher education rates and growth in the urban population, which have been quite large between 1982 and 2006. The previous research found that women with higher education, living in urban areas are more likely to choose condom or other short-term methods (Wang 2010b). Understanding shifts in contraceptive method choice is important to help policymakers and program managers meet current contraceptive demand and future needs.

The results (Table 2) show that among "new users", between the study periods 1996-2001 and 2001-2006, there has been an increase in condom use after the first birth and in IUD use after the second birth, both of which represent a move away from the methods traditionally being promoted under China's FPP at these parities. The study found that women using a policy-driven method fell significantly between the two study periods, even after controlling for parity, age, year of marriage, motivator of current method use, and other social variables 
(Table 3 and Table 4). This suggests that the national reform program of "Quality of Care" was generally successful in weakening the top-down policy of enforcing specific methods by promoting a shift towards client-centred family planning services based on the principle of enabling users to make an informed choice of method. This is also supported by the evidence that more women and couples are choosing the method motivated by themselves, rather than by family planning workers; and more women understand the characteristics of the method which imply that women are benefitting from method counselling. However, the significant province and county level variation suggests the possible continuation of the rigid top-down approach in family planning system. There is no statistical evidence of any change in this respect between the two time periods. The individual-level results support the evidence that family planning workers still have some influence in promoting the use of policy-driven methods. These results are highly consistent with a previous study (Brown, Li and Padmadas 2010), which indicated that the reforms of the family planning program that occurred in the limited number of pilot counties have also been replicated nationwide.

Furthermore, our analysis highlights that contraception provision and local method mix also plays an important role for informed choice (Table 5). Women living in those communities with a wider choice of methods have higher odds of informed choice than those living in the community with less varied method provision, after controlling for women's individual characteristics. A wider variety of contraception provision might also link to greater exposure to family planning information, counselling and interpersonal communication, which help to inform clients about the range of contraceptives available to them and enable them to make an informed and voluntary choice of the method they wish to use (Philips et al 1988; Liu 2004; Wu 2008b). Interestingly, in comparison with those using an IUD, women who had sterilization have a lower odds of having made an informed choice. The explanation may be that sterilization is likely to be motivated by family planning workers; and the side effect of surgery itself may be more difficult to understand without adequate counselling. Women living in the central region have the lowest odds of informed choice of contraception compared with those in eastern and western region. Probability this is because the speed of scaling up program of Quality of Care in family planning services is more slowly in this region. The results therefore highlight the need for further programme and policy interventions, such as enhanced method choice counselling and that more work needs to be done within the central provinces. 
Promoting access to contraceptives has been acknowledged to be effective on fertility decline and achieving sexual and reproductive health in developing countries (Tsui and Bogue 1978; Hardee, Xie and Gu 2004; Bongaarts and Sinding 2011; World Health Organization (WHO) 2014). The principles of informed and voluntary decision making are not new. It requires service options to be available; the decision-making process to be voluntary; individuals to have access to appropriate information; good client-provider interaction including counselling ensured; and the social and political context to be in place to support autonomous decision making (WHO 2014). Before 1994, these principles were largely missing in Chinese family planning programmes. The social and political context was not supportive for individual's independent decision making. The programmes promote IUD and sterilization as the preferred contraceptive method. Most women had very limited choice, but been enforced IUD insertion after the first birth and sterilization after the second birth, with little access to appropriate information and counselling. Individuals who violated the enforcements may encounter socio-economic disincentives. Following the principle of ICPD in Cairo in 1994 and the Bruce framework of quality of care (Bruce 1990), contraception services in China began to refocus on clients' needs, informed choice and better quality services. The reform activities included expanding the range of contraceptive methods available and enabling individuals and couples to make informed decisions about which method to use without any form of coercion and discrimination by the authorities. The pilot program of Quality of Care in family planning services in China started in the early 1990s. The initial small scale pilot project has since been scaled up into a national reform program in 2000s (Kaufman, Zhang and Xie 2006). Over the last 20 years, much progress has been made in China in building a consensus for the principles of individual choice in family planning, and large investments have been made to develop counselling training and services. The coercive enforcement of sterilization and IUD use has been weakening over time. The new client-centred programme broadened women's contraceptive options and choices, with greater levels of informed choice, counselling and follow-up. However despite considerable advances in support of informed and voluntary decision making in contraception choices, a wide gap still exists. This paper presents substantial evidence that the changes differ between social groups. Women with less education, those living in rural areas and those living in the central region are vulnerable in informed choice regarding contraception autonomous decision making and side effects. Because the majority contraceptives are provided free of charge, financial cost does not play 
the main role in determining an individual's choice of method. Barriers to informed and voluntary decision making persist for many reproductive health care clients as a result of local regulations, service-delivery practices, resource constraints (inadequate counselling), and service providers' attitudes (Wu 2008a; Kaufman, Zhang and Xie 2006).

The present study is the first of its kind in China applying national representative data to exam the effect of national reform program of quality of care. Although the change refocusing on clients' needs, informed choice and better quality services started in mid-1990s, it was very small scale pilot project and scaled up to national reform program after 2000. Thus the multivariate analysis compares data from 1996-2001 and 2001-2006 could largely capture the effect of changes in FPP programme on contraceptive behaviour. However, given the cross sectional characteristics of the data set, I could not precisely compare women with intervention and those without intervention. Instead, I could only roughly divide women into two times period where the scaled intervention occurred in the second time period. Future research should consider using panel data to compare interventions and non-interventions to examine such influences. In the study surveys, contraception use data was collected only from married women. The future survey should also consider men, adolescent and young women, because adolescent and young women generally have limited access than older individuals to family planning methods; and male participation in family planning has been influencing in the contraceptive negotiation (Mason and Smith 2000).

\section{Appendix}

Table 6. Odds Ratios of Using a Policy-Driven Method from Different Motivators by Parity among Han and Non-Han Ethnic Groups

\begin{tabular}{lllllllll}
\hline & \multicolumn{4}{c}{ Han } & \multicolumn{4}{c}{ Non-Han } \\
\hline \multirow{3}{*}{ Woman } & Couple & FP & Other & Woman & Couple & FP & Other \\
warity1 & 1.00 (reference) & 0.40 & 1.92 & 0.55 & 1.40 & 0.57 & 2.69 & 0.78 \\
Parity2 & 0.12 & 0.33 & 0.79 & 0.27 & 0.05 & 0.15 & 0.35 & 0.12 \\
\hline
\end{tabular}

Source: derived from Table 4. 


\section{Reference}

Brown,J., Li, B.H. and Padmadas, S. (2010). A multilevel analysis of the effects of a reproductive health programme that encouraged informed choice of contraceptive method rather than use of officially preferred methods, China 2003-2005. Population Studies. 64 (2):105-115.

Bongaarts, J., and S. Sinding. (2011). Population Policy in Transition in the Developing World. Science, 333:574-575.

Bruce,J. (1990). Fundamental elements of the quality of care: a simple framework. Studies in Family Planning. 21(2):61-91.

Gu, B.C., Wang, F., Guo, Z.G., and Zhang E.L. (2007). China's local and national fertility policies at the end of the twentieth century. Population and Development Review 33(1): $129-147$

Hardee,K., Xie, Z.M. and Gu, B.C. (2004). Family planning and women's lives in rural China. Internal Family Planning Perspectives. 30 (2): 68-76.

Jain, A.K. (1989. Fertility reduction and the quality of family planning services. Studies in Family Planning. 20(1):1-16.

Kaufman, J., Zhang, E.L. and Xie, Z.M. (2006). Quality of care in China: scaling up a pilot project into a national reform program. Studies in Family Planning. 37 (1):17-28.

Khan,H.R. and Shaw, J. E. (2011). Multilevel Logistic Regression Analysis Applied to Binary Contraceptive Prevalence Data. Journal of Data Science 9, 93-110.

Li, J.M (2009). Fertility revolution in China. Population Research, 33(1):1-9.

Liu, Y.R. (2004). Contraception use among married women in China. Chinese Journal of Family Planning. 5:260-262.

Magadi, M.A. and Curtis, S.L. (2003). Trends and determinants of contraceptive method choice in Kenya. Studies in Family Planning. 34(3):149-159.

Mason, K.O., Smith, H.L. (2000) Husbands' versus wives' fertility goals and contraceptive use: The influence of gender context in five Asian countries. Demography, 37: 299-312.

National Population and Family Planning Commission (NPFPC) edit. (2007). History of China Population and Family Planning. China Population Press: Beijing.

Philips,J.F., Simmons, R., Koening, M.A., and Chakraborty,J. (1988). Determinants of reproductive change in a traditional society: evidence from Matlab, Bangladesh. Studies in Family Planning. 19(6):313-334. 
Qin, M (2016). Evolution of family planning policy and its impact on population change in china. PhD thesis. University of Southampton, Social Sciences: Social Statistics \& Demography.

Rasbash, J., Steele, F., Browne, W. and Goldstein,H. (2009). A user's guide to mlwin. Version 2, Centre for Multilevel Modelling, University of Bristol, UK.

Ross, J., Hardee, K., Mumford, E., and Eid, S. (2001). Contraceptive Method Choice in Developing Countries. International Family Planning Perspectives, 28(1):32-40.

Ren,Q. and Zheng,X.Y. (2006). Behaviour change of Chinese married women on contraception use: 1988-2001. Chinese Journal of Population Science. 3: 28-38.

Reng,N., Su, P., Guang, H.T., Wu, C.J., Zhou, J.L., Su, N., Liao, J.Y. and Xiong, C.L. 2003. Analysis on influencing factor for informed choice of family planning among rural women. Chinese Journal Public Health. 19(11):1288-1289.

Seiber, E.E. Bertrand, J.T. and Sullivan,T.M. (2007). Changes in Contraceptive Method Mix In Developing Countries. International Family Planning Perspectives. 33(3):117-123.

Steele, F., Curtis,S.L. and Choe,M.K. (1999). The impact of family planning service provision on contraceptive use dynamics in Morocco, Studies in Family Planning 30(1): $28-42$.

Stephenson, R. and Tsui,A.O. (2002). Contextual influences on reproductive health service use in Uttar Pradesh, India, Studies in Family Planning 33(4):309-320.

Tsui, A. O. and D. Bogue. (1978). Declining World Fertility: Trends, Causes and Implications. Population Bulletin 33(4):2-56.

The Johns Hopkins School of Public Health. (1989). Informed choice: Report of the cooperating agencies task force. Baltimore, ML: Johns Hopkin Press.

Wang, C. (2012a). History of the Chinese Family Planning program: 1970-2010. Contraception, 85, 563-569.

Wang, C. (2012b).Trends in contraceptive use and determinants of choice in China:19802010. Contraception 85: 570-579.

World Health Organization (WHO). (2014). Ensuring human rights in the provision of contraceptive information and services Guidance and recommendations. WHO, Luxembourg.

Wu, J.Q. (2008). Counselling about informed choice of contraception. Chinese Journal of Family Planning. 3:132-136. 
Wu,S.C. (2008). Side effect of contraceptives and informed choice of contraception. Journal of Obstetrics and Gynecology. 24(3):143-44.

Xie, Z.M. (2011) Focusing on quality of care in the Family Planning Programme.

http://ssc.undp.org/content/ssc/library/solutions/partners/gssdAcademy/Volume_19_E xperiences_in_Addressing_Population_and_Reproductive_Health_Challenges.html

Zhang, Y.Z. (2007). Factors influence contraceptive informed choice among rural women in Henan Province. Population Research 31(4):89-96. 